\title{
Co-Inhibitors of Second Signal of Lymphocyte Response in Human Renal Transplants: PD-L2, GITR, and ILT-2/3/5 Positive Cells from Aspiration Biopsies Associate with Acute Rejection-Freedom
}

\author{
Paula D. P. Xavier ${ }^{1}$, José Gerardo G. Oliveira ${ }^{2,3^{*}}$ \\ ${ }^{1}$ Instituto Português do Sangue e da Transplantação, Área Transplantação, Rua do Bolama, Porto, Portugal \\ ${ }^{2}$ GCCT, Centro Hospitalar Universitário S. João, Alameda Hernâni Monteiro, Porto, Portugal \\ ${ }^{3}$ CINTESIS, Faculdade de Medicina da Universidade do Porto, Alameda Hernâni Monteiro, Porto, Portugal \\ Email: *marilu@med.up.pt
}

How to cite this paper: Xavier, P.D.P. and Oliveira, J.G.G. (2021) Co-Inhibitors of Second Signal of Lymphocyte Response in Human Renal Transplants: PD-L2, GITR, and ILT-2/3/5 Positive Cells from Aspiration Biopsies Associate with Acute Rejection-Freedom. Open Journal of Nephrolo$g y$, 11, 58-77.

https://doi.org/10.4236/ojneph.2021.111006

Received: February 2, 2021

Accepted: March 15, 2021

Published: March 18, 2021

Copyright $\odot 2021$ by author(s) and Scientific Research Publishing Inc. This work is licensed under the Creative Commons Attribution International License (CC BY 4.0).

http://creativecommons.org/licenses/by/4.0/

\begin{abstract}
Following organ transplantation, the outcome of the encounter between an APC and a T lymphocyte is strongly dependent on the presence of costimulatory and co-inhibitory molecules, the former associated with allograft rejection and the latter with allograft acceptance. We evaluated the expression of PD-L2, GITR, ILT-2/3/5, and ILT-4 on graft-infiltrating cells procured by Fnab from human KTx under different immunosuppressive regimens. Methods: Fnab biopsies were performed on days 7 or $14-30$ in stable KTx and on the day of acute rejection diagnosis. Cytopreparations were studied by the enzymatic avidin biotin complex staining. Results: Acute rejection group showed a significant down-regulated expression of PD-L2, GITR, and ILT-2/3/5 as compared to stable group, while for ILT-4 we did not find significant difference. Anti-IL $2 \alpha$ R and rapamicyn treatment trend to down-regulate ILT-4 expression, although meaningless. A significantly positive correlation was observed between PD-L2 and GITR expression in Fnab. The PPV for acute rejection diagnosis for both PD-L2 and GITR was clearly above 0.8 . Conclusions: Our findings point to an early entrance of cells expressing PD-L2, GITR and ILT-2/3/5 inside human KTx who are going to remain rejection-free. Both PD-L2 and GITR shared a high ability to rule-in and rule-out acute rejection.
\end{abstract}

\section{Keywords}

Antigen-Presenting Cell, Fine-Needle Aspiration Biopsy, 
Glucocorticoid-Induced Tumor Necrosis Factor Receptor, Immunoglobulin-Like Transcript, Kidney Transplant, Programmed Death-Ligand 2

\section{Introduction}

Organ transplantation walked a very long, exigent and exciting road. Coming from the first laboratory experiments which raised deep reservation for its feasibility [1], passing through a long period of scarce therapeutic alternatives to prevent/treat acute rejection episodes, currently, human kidney transplants (KTx) enjoy an excellent short-term outcome although less than optimal long-term survival [2]. The underlying causes of KTx failure are diverse and have quite different frequencies depending on the time interval from the surgical procedure but immune-mediated injury occupies a central role [2] [3], notwithstanding the significant betterments of immunosuppressive drugs developed during the last four decades. Rejection of KTx, or for that matter of any other organ transplant demands an elaborate cooperation between different cells and their products. In order to kindle the rejection process, antigen must be processed and presented to a lymphocyte but this step is not able de per se to start the reaction, and a second step of cell activation is needed, both on the antigen-presenting cell (APC) and on the responder cell [4], to reach maximal efficacy and escape from anergy/ignorance. This concept of a second costimulatory signal was first introduced by Lafferty and Woolnough [5] and several molecules performing this role had been identified [6]. It did not take long that the list of stimulating molecules pertaining to this second signal was accrued by inhibitory ones [7]. The presence of co-inhibition molecules expressed on APC may polarize T lymphocytes into a regulatory mode [7] [8] which seems to constitute a major contributor for KTx survival [9]. Furthermore, these regulatory T cells can deploy reverse signalling and enhance the tolerogenic potential of APC [10]. Already, some of these co-inhibitory molecules have found their way into randomized clinical trials to explore their potential as treatment of several clinical conditions, both as enhancers of a tolerance status [11], the case of transplant, and as enhancers of immune reaction through their inhibition [12], the case for neoplasic patients.

As it was observed concerning costimulatory molecules, the functional importance may not be the same for every co-inhibitory one and, not unexpectedly, some controversy remains about descriptions of their full effects, how immunosuppressive drugs affect them as well as their associations with clinical events in human transplantation [13] [14] suggesting that a lot can be gained through a more comprehensive knowledge how they operate. Per se fine-needle aspiration biopsy (Fnab) in KTx, described by P. Haÿry [15] has not reached a desirable level of diagnostic accuracy and does not grant a structural definition of the events occurring inside a KTx. However, when Fnab samples are further 
analysed by flow cytometry, they provide the answer as to whether the KTx is developing an acute rejection or not, with very high reliability [16], which is the main question arising at the time they are done. Of importance, when compared with peripheral blood, Fnab samples display significant differences for several $\mathrm{T}$ cell subsets [17] raising doubts over whether studies of peripheral blood can be an accurate mirror of what is happening inside the graft. Although it may be possible to identify markers at the peripheral blood level that correlated with clinical status, monitoring or even prediction of events, being associated with minimum discomfort to the patient while at the same time, escaping the variability inherent to the samples procured by Fnab. In a way, after going through the organ "sink" what is seen in circulation may bring powerful information notwithstanding the distance/deviation from the intra-graft events, which for some factors may actually behave as mirror images. These limitations being acknowledged, we took advantage of our Fnab KTx program, to get an easy and ethically acceptable gateway into KTx immune events.

We studied the presence of Programmed death-ligand 2 (PD-L2), Glucocorticoid-induced tumor necrosis factor receptor (GITR) and Immunoglobulin-like transcripts (ILT-2/3/5 and -4) in Fnab, performed in KTx both in stable cases during the first month post-surgery and whenever an acute rejection episode was diagnosed and confirmed by a classical biopsy. Our interest was focused on the associations between these molecules and the clinical situation, knowing the controversial findings concerning the first two, PD-L2 and GITR, and looking at the potential modifications on their expression brought about by different immunosuppressive regimens. We decided to study their protein expression recurring to classical immunocytochemistry methods.

\section{Materials and Methods}

Table 1 summarizes patient's demographics and characteristics.

Patients: This study included $129 \mathrm{KTx}, 77$ males and 52 females, aged 20 to 65 years. Each patient provided adequate Fnab samples according to P Haÿry [15] criteria and all received an organ from a deceased donor. The study group included cases whenever Fnab was possible for logistic reasons, when the patient agreed to participate, which was close to $90 \%$ of demands, and when the sample proved to be of quality according to P Haÿry [15]. Actually, acute rejection frequency of KTx in the transplant unit averages $15 \%$ of cases.

All patients were treated from the outset with a calcineurin inhibitor (CNI), 98 with cyclosporine A (CsA) and 31 with tacrolimus (TAC), plus mycophenolate mofetil (MMF) and prednisolone, excepting second grafts that received quadruple therapy including two to five doses of thymoglobulin, depending on the number of blood lymphocytes. Likewise, in seven first KTx rapamycin (RAPA) substituted for MMF and in seven first KTx a chimeric anti-IL2 $\alpha$ receptor antibody (anti-IL2 $\alpha$ R) was administered twice. The therapeutic levels in whole blood for CsA, TAC and RAPA, during the first three months post-KTx were $150-250 \mathrm{ng} / \mathrm{ml}, 6-12 \mathrm{ng} / \mathrm{ml}$ and $4-12 \mathrm{ng} / \mathrm{ml}$, respectively. 
Table 1. Demographics and characteristics. Values are reported in the given units and all comparisons between groups were nonsignificant, except serum creatinine that was higher in recipients with AR ( $\mathrm{p}=0.002)$. Recipients are all adult, aged between 20 - 65 years old and transplanted with kidney deceased donors. AR diagnosis were done on the biopty-gun biopsy, done at the same time as Fnab, and classified according to Banff criteria and secured by a positive response to treatment or by histologic reassessment of graft nephrectomy. DN-diabetes mellitus, IgA-IgA nephropathy, RPGN-rapidly progressive glomerulonephritis, SLE-systemic lupus erythematous, FSGS-focal segmental glomerulosclerosis, TIN-tubulointerstitial nephritis, HTN-hypertension, CGN-chronic glomerulonephritis, PKD-adult polycystic kidney disease, DGF-delayed graft function.

\begin{tabular}{|c|c|c|c|}
\hline Phenotype characteristic & $\begin{array}{l}\text { All Ktx recipients } \\
\qquad(\mathrm{n}=129)\end{array}$ & $\begin{array}{l}\text { Stable recipients } \\
\qquad(\mathrm{n}=92)\end{array}$ & $\begin{array}{l}\text { Rejection recipients } \\
\qquad(\mathrm{n}=37)\end{array}$ \\
\hline \multicolumn{4}{|l|}{ Gender } \\
\hline Female & 52 & 38 & 14 \\
\hline Male & 77 & 54 & 23 \\
\hline \multicolumn{4}{|l|}{ Cause of ESRD } \\
\hline $\mathrm{DN}$ & 24 & 18 & 6 \\
\hline IgA & 14 & 10 & 4 \\
\hline RPGN & 9 & 4 & 5 \\
\hline SLE & 5 & 3 & 2 \\
\hline FSGS & 8 & 7 & 1 \\
\hline TIN & 35 & 25 & 10 \\
\hline HTN & 6 & 4 & 2 \\
\hline CGN & 20 & 15 & 5 \\
\hline PKD & 8 & 6 & 2 \\
\hline \multicolumn{4}{|l|}{ Immunosupression } \\
\hline CsA & 98 & 71 & 27 \\
\hline RAPA & 7 & 6 & 1 \\
\hline MMF & 25 & 15 & 10 \\
\hline Anti-IL2aR & 7 & 7 & 0 \\
\hline \multicolumn{4}{|l|}{$\mathrm{Ktx}$} \\
\hline First & 121 & 87 & 34 \\
\hline Re-Ktx & 8 & 5 & 3 \\
\hline DGF & 23 & 15 & 8 \\
\hline Serum Creatinine & NA & 2.8 & 4.9 \\
\hline
\end{tabular}

Nintety-two patients remained rejection-free for the first year post-KTx, at least, and thirty-seven developed an acute rejection episode at a median of 15 \pm 430 days post-KTx. Twenty-two rejections occurred during the first month, five on second and third month, and ten cases beyond. Twenty-seven of these patients were treated with CsA and ten with TAC, including one treated with RAPA and three with quadruple therapy. Every acute rejection episode was di- 
agnosed by a biopty-gun biopsy done at the same time as the Fnab and read by an independent pathologist according Banff criteria. Rejection diagnosis was further secured by either a positive response to treatment or by histologic reassessment of graft nephrectomy. Acute rejection was treated with either 1) 3 pulses of IV 250 - $500 \mathrm{mg}$ methylprednisolone, 2) thymoglobulin, minimum of two doses, or 3) 5 - 12 sessions of plasmapheresis and IgG at $0.4 \mathrm{gr} / \mathrm{kg}$ weight, if the episode was graded IIa or greater, or when C4d positivity was observed along with donor-specific antibodies. Only one case was proved to be treatment resistant, and this patient suffered a transplantectomy at the third week post-KTx.

All patients received prophylaxis with ganciclovir/valganciclovir when donor was positive and recipient was negative for $\mathrm{CMV}$, and whenever thymoglobulin was administered. Furthermore, each KTx received cotrimoxazol as prophylaxis for Pnemocystis jirovecii during the first six to twelve months post-surgery.

Methods: Among the rejection-free cases, Fnab was done on days 7, 14 or 30 post-KTx, 90 - $150 \mathrm{~min}$ after the morning intake of immunosuppressive drugs, and on the day of the biopty-gun biopsy among rejection cases. Cytoslides were prepared with Fnab samples submitted to a $700 \mathrm{rpm}$ cytocentrifugation for 10 min and kept at $-70^{\circ} \mathrm{C}$ until use. Later, those were brought back to room temperature and submitted to immunocytochemistry staining by the enzymatic Avidin Biotin Complex $(\mathrm{ABC})$ method using the detection system UltraVision $^{\mathrm{TM}}$, HRP/DAB (Horseradish Peroxidase/Three, 3'Diaminobenzidine Tetrahydrochloride) from Thermo Scientific, UK. All the incubations were done at room temperature. Briefly, cytoslides were hydrated in ethanol $95^{\circ}$ and incubated with $\mathrm{H}_{2} \mathrm{O}_{2}$ during 15 min for peroxidase blocking, rinsed in distilled water and Tris Buffered Saline (TBS) solution at $\mathrm{pH}=7.4$. Nonspecific immunoglobulins were blocked with Ultra V Block from Lab Vision ${ }^{\mathrm{TM}}$ during $10 \mathrm{~min}$, followed by the addition of a pre-determined dilution of the primary antibody and 60 minutes of incubation. At the end cytoslides were washed and dipped in TBS for $10 \mathrm{~min}$, just before the addition of $4 \mu \mathrm{g} / \mathrm{ml}$ of rabbit anti-goat secondary antibody and 10 min of incubation. After rinsing the secondary antibody excess with TBS, 10 min of incubation with Streptavidin Peroxidase was done before the addition of DAB Chromogen and DAB Substrate. Finally, hematoxylin from Mayer's Hematoxylin, DakoCytomation was applied, followed by dehydration with ethanol $95^{\circ}$ and coverslip with Entellan ${ }^{\circledR}$ mounting medium.

Primary antibodies used included a goat $\mathrm{IgG}$ at a $15 \mu \mathrm{g} / \mathrm{ml}$ (reference $\mathrm{AF}$ 1224) for PD-L2, a goat IgG at $15 \mu \mathrm{g} / \mathrm{ml}$ (reference AF 689) for GITR both from $\mathrm{R} \& \mathrm{D}$, a goat polyclonal IgG at $8 \mu \mathrm{g} / \mathrm{ml}$ (reference sc-33453) for ILT-2/3/5 and a goat polyclonal IgG at $4 \mu \mathrm{g} / \mathrm{ml}$ (reference sc-33455) for ILT-4, both acquired from Santa Cruz Biotechnology, Inc. On each cytoslide, every kidney tubular cell (R) was counted as well as every negative and positive lymphocyte and monocyte-macrophage (LM) for the antibody, in order to assess the absolute values of positive cells as well as the ratio of positive cells for both R and LM cells in an 
attempt to correct the cell variation observed in Fnab sample contents.

Statistical analysis: The statistical analysis included the determination of median, SD, and interquartile ranges for the studied molecules. Comparisons for serum creatinine and whole blood immunosuppressive drugs were done by unpaired Student's T test, and comparative analysis of molecules results were done by Mann-Whitney U test. The correlations between molecules were tested using Spearman correlation and sensitivity, specificity, negative predictive value (NPV), positive predictive value (PPV) and positive and negative likelihood ratios were establish when indicated.

This study was approved by the Faculty of Medicine of University of Porto and University Hospitalar Center of S. João of Porto joint Committee of Ethics. Informed consent was obtained from each patient and the study was conducted in compliance with the Good Clinical Practice Guidelines declaration of Helsinki and Istanbul.

\section{Results}

The median and interquartile range for serum creatinine among rejection-free cases on day 7 post-KTx was $2.8 \mathrm{mg} / \mathrm{dl}$ and $1.6-7 \mathrm{mg} / \mathrm{dl}$, respectively and 4.9 $\mathrm{mg} / \mathrm{dl}$ and $2.6-10 \mathrm{mg} / \mathrm{dl}$, respectively for acute rejection group $(\mathrm{P}=0.002), 2.5$ $\mathrm{mg} / \mathrm{dl}$ and $1.6-10 \mathrm{mg} / \mathrm{dl}$ on days $14-30$ post-KTx $(\mathrm{P}>0.05$ on comparing day seven with day 14 - 30 within stable cases; $\mathrm{P}=0.009$ when comparing day 14-30 with acute rejection day). Fifteen cases of delayed graft function were remarked among rejection-free cases and eight among acute rejection cases. The whole blood levels for CsA, TAC and RAPA were within the limits of the transplant unit protocol in almost every case and no episode of CNI toxicity, clinical CMV disease or BK poliomavirus infection occurred. However, both CsA and TAC blood levels were significantly inferior among acute rejection $\mathrm{KTx}, \mathrm{P}<0.000$ and $\mathrm{P}=0.005$, respectively. Also, no significant difference was observed when comparing HLA matching for rejection-free cases with acute rejection cases but a significant correlation was observed between the presence of anti-HLA antibodies pre-KTx and acute rejection $(\mathrm{P}=0.002)$.

Forty-eight patients were studied for PD-L2. All received CNI and none was treated with RAPA or anti-IL $2 \alpha$ R. Twenty-seven remained rejection-free for the first year post-KTx, at least. Amongst the stable group, Fnab was done on day seven post-KTx in twenty-one cases and on the $9^{\text {th }}, 11^{\text {th }}, 13^{\text {th }}, 15^{\text {th }}$ and $16^{\text {th }}$ and $34^{\text {th }}$ day post-KTx. Acute rejection events occurred in the first month post-KTx in nine cases, two during the second and third month and nine episodes were diagnosed after the third month post-KTx. In Table 2 we present PD-L2 results. A highly significant difference was observed concerning PD-L2 expression which was up-regulated in stable KTx Fnab samples compared to acute rejection cases, whether relating the absolute number of positive cells, $\mathrm{P}=0.00004$, the ratio of positive cells over $\mathrm{R}$ cells, $\mathrm{P}=0.0005$, or the ratio of positive cells over LM, $\mathrm{P}=0.00002$.

A total of forty-nine cases were studied for GITR, but two were excluded, because one was treated with anti-IL $2 \alpha \mathrm{R}$ antibody and the other with RAPA, leaving 
Table 2. Results for PD-L2 expression in Fnab samples presented as median/SD and interquartile ranges and expressed as absolute number of positive cells, ratio of positive cells over number of renal cells $(\mathrm{R})$ and ratio of positives cells over the number of lymphocytes plus monocytes-macrophages (LM).

\begin{tabular}{cccc}
\hline PD-L2 & $\begin{array}{c}\text { Stable } \\
n=27\end{array}$ & $\begin{array}{c}\text { Acute rejection } \\
n=21\end{array}$ & $\begin{array}{c}\text { Mann-Whitney } \\
\boldsymbol{P}\end{array}$ \\
\hline \multirow{2}{*}{ Absolute number } & $145 \pm 129$ & $22 \pm 33$ & $\mathbf{0 . 0 0 0 0 4}$ \\
& {$[46-191]$} & {$[2-23]$} & \\
+cells/R cells & $0.54 \pm 0.89$ & $0.14 \pm 0.24$ & $\mathbf{0 . 0 0 0 5}$ \\
& {$[0.11-0.55]$} & {$[0.004-0.15]$} & \\
+ cells/LM cells & $0.42 \pm 0.32$ & $0.13 \pm 0.26$ & $\mathbf{0 . 0 0 0 0 2}$ \\
\hline
\end{tabular}

forty-seven. Twenty-eight were stable $\mathrm{KTx}$ and nineteen were acute rejection cases which occurred during the first month in eleven patients, five between the second and the twelfth month, one case two years post-KTx, and two cases four years post-KTx. In Table 3, we present GITR results which showed a significantly higher expression among stable cases either by comparing the absolute numbers of positive cells, $\mathrm{P}=0.0000$, the ratio of positive cells over $\mathrm{R}$ cells, $\mathrm{P}=$ 0.00001 or the ratio of positive cells over LM cells, $\mathrm{P}=0.00002$. In Table 4 and Table 5 are the results for acute rejection diagnostic performance, following the analysis for cut-off points, for PD-L2 and GITR respectively, which reached unanticipated very high values. Also, in Figure 1 and Figure 2, we show the results assessed for AUC of the ROC curves and the distribution of non-rejection patients and acute rejection group, either for absolute numbers of positive cells, ratio of positive cells over R cells or ratio of positive cells over LM cells, for PD-L2 and GITR respectively. In twenty-three cases PD-L2 and GITR were analysed simultaneously, eighteen stable cases and five acute rejection KTx; the Spearman correlation was $0.58, \mathrm{P}=0.002$.

Twenty-five KTx were studied for ILT-2/3/5, but as two cases were treated with anti-IL $2 \alpha$ R antibody they were excluded, leaving twenty-three cases. Eleven patients were treated with CNI and five with RAPA within the stable group, and seven KTx suffered acute rejection. Rejection episodes occurred within the first month post-surgery in four cases and the others on days 200, 1000 and 2100 post-transplantation. Results are presented in Table 6. No significant difference was observed by comparing stable cases treated with $\mathrm{CNI}$ versus those receiving RAPA, either for absolute number, $\mathrm{P}=0.81$, ratio over $\mathrm{R}$ cells, $\mathrm{P}=0.28$ or ratio over LM, $\mathrm{P}=0.72$. We decided to combine the results of CNI with RAPA therapy for comparative analysis with acute rejection. ILT-2/3/5 expression was significantly up-regulated in stable patients, with $\mathrm{P}=0.049$ for absolute number of positive cells, $\mathrm{P}=0.026$ for the ratio of positives over renal cells and $\mathrm{P}=0.031$ for positives over LM cells ratio.

A total of thirty-nine KTx were studied for ILT-4, nineteen treated with CNI, six with RAPA and five with anti-IL2 $\alpha$ R antibody, all stable KTx. Acute rejection 
Table 3. Results for GITR positives in Fnab samples presented as median/SD and interquartile ranges and expressed as absolute number of positive cells, ratio of positive cells over the number of renal cells (R) and ratio of positives cells over the number of lymphocytes plus monocytes-macrophages (LM).

\begin{tabular}{cccc}
\hline GITR & Stable & Acute rejection & Mann-Whitney \\
& $n=28$ & $n=19$ & $\boldsymbol{P}$ \\
\hline \multirow{2}{*}{ Absolute number } & $73 \pm 43$ & $8.8 \pm 7.9$ & $<0.0000$ \\
& {$[49-103]$} & {$[2.5-14.5]$} & \\
+ cells/R cells & $0.19 \pm 0.18$ & $0.037 \pm 0.04$ & $<0.00001$ \\
& {$[0.07-0.28]$} & {$[0.007-0.05]$} & \\
+ cells/LM cells & $0.21 \pm 0.19$ & $0.06 \pm 0.09$ & $<0.00002$ \\
\hline
\end{tabular}

Table 4. Diagnostic performance for PD-L2. The cut-off points for absolute number of positives, ratio of positives over number of renal cells $(R)$ and ratio of positives cells over number of lymphocytes plus monocytes-macrophages (LM) were $34,0.035$ and 0.13 , respectively.

\begin{tabular}{cccc}
\hline PD-L2 & Absolute number & Pos cells/R & Pos cells/LM \\
\hline Sensitivity & 0.846 & 0.962 & 0.846 \\
Specificity & 0.818 & 0.591 & 0.864 \\
Positive predictive value & 0.846 & 0.735 & 0.880 \\
Negative predictive value & 0.818 & 0.929 & 0.826 \\
Positive likelihood ratio & 4.654 & 2.350 & 6.205 \\
Negative likelihood ratio & 0.188 & 0.065 & 0.178 \\
\hline
\end{tabular}

Table 5. Diagnostic performance for GITR. The cut-off points for absolute number of positives, ratio of positives cells over number of renal cells $(\mathrm{R})$ and ratio of positives cells over number of lymphocytes plus monocytes-macrophages (LM) were 29, 0.047 and 0.06, respectively.

\begin{tabular}{cccc}
\hline GITR & Absolute number & Pos cells/R & Pos cells/LM \\
\hline Sensitivity & 0.929 & 0.893 & 0.857 \\
Specificity & 1.000 & 0.737 & 0.737 \\
Positive predictive value & 1.000 & 0.833 & 0.828 \\
Negative predictive value & 0.905 & 0.824 & 0.778 \\
Positive likelihood ratio & $\infty$ & 3.393 & 3.257 \\
Negative likelihood ratio & 0.071 & 0.145 & 0.194 \\
\hline
\end{tabular}

Table 6. Results for ILT-2/3/5 positives in Fnab samples presented as median/SD and interquartile ranges and expressed as absolute number of positive cells, ratio of positive cells over number of renal cells $(\mathrm{R})$ and ratio of positives over the number of lymphocytes plus monocytes-macrophages (LM).

\begin{tabular}{ccccc}
\hline & \multicolumn{2}{c}{$\begin{array}{c}\text { Stable } \\
\text { (Stb) }\end{array}$} & $\begin{array}{c}\text { Acute Rejection } \\
\text { ILT) }\end{array}$ & \\
\cline { 2 - 4 } & CNI & RAPA & $n=7$ & Mann-Whitney \\
& $n=11$ & $n=5$ & $P$ & \\
\hline \multirow{2}{*}{ Absolute number } & $16 \pm 28$ & $6.4 \pm 5.1$ & $5.4 \pm 14.3$ & CNI vs RAPA:0.81 \\
& {$[0-31]$} & {$[3-11]$} & {$[0-0]$} & Stb vs AR: 0.049 \\
\hline
\end{tabular}




\section{Continued}

\begin{tabular}{ccccc}
\hline & $0.029 \pm 0.035$ & $0.09 \pm 0.1$ & $0.009 \pm 0.026$ & CNI vs RAPA: 0.28 \\
+ cells/R cells & {$[0-0.07]$} & {$[0.021-0.12]$} & {$[0-0]$} & Stb vs $A R: 0.026$ \\
& $0.06 \pm 0.017$ & $0.05 \pm 0.064$ & $0.014 \pm 0.04$ & CNI vs $R A P A: 0.72$ \\
+ cells/LM cells & {$[0-0.13]$} & {$[0.017-0.05]$} & {$[0-0.11]$} & Stb vs AR: 0.031 \\
\hline
\end{tabular}
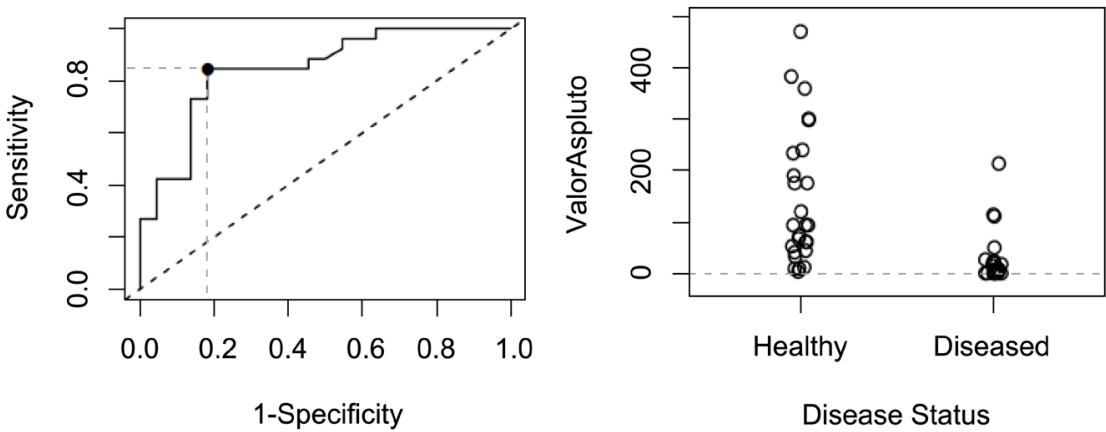

(A)
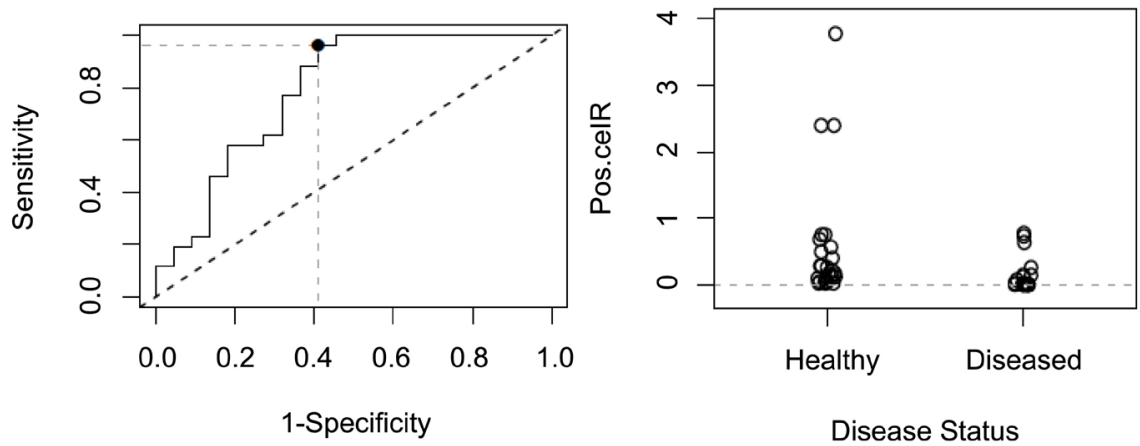

(B)

Disease Status
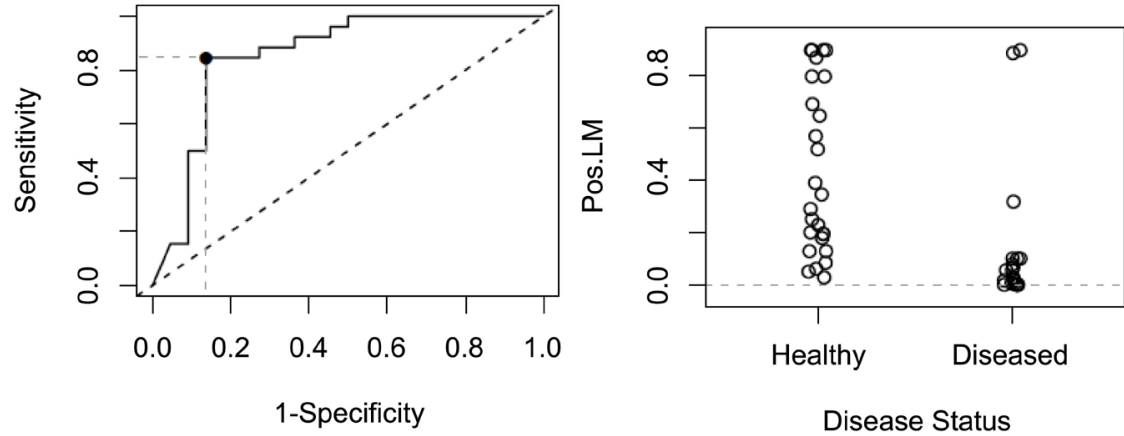

(C)

Disease Status

Figure 1. PD-L2 co-inhibitor could segregate nonrejection (NR) patients from those with acute rejectin (AR). The score model was practiced on $27 \mathrm{NR}$ and $21 \mathrm{AR}$ samples to generate a scale Q score ranging from 0 to 100 for Valor Absoluto (VA), from 0 to 4 and 0 to 1 for PosCelR and PosLM ratios respectively. The AUC of the ROC curves and the disribution of $\mathrm{NR}$ and $\mathrm{AR}$ are shown in the figure. (A) For VA the Youden optimal cut-off method set a threshold at 34 with a corresponding sensitivity of $84.6 \%$ and specificity of $81.8 \%$. The AUC of the ROC curve was 0.847 ( $\mathrm{p}<0.000)$. (B) For the ratio PosCelR the Youden optimal cut-off method set a threshold at 0.035 with a corresponding sensitivity of $96.2 \%$ and specificity of $59.1 \%$. The AUC of the ROC curve was 0.790 (p $<0.000$ ). (C) For the ratio PosLM the Youden optimal cut-off method set a threshold at 0.13 with a corresponding sensitivity of $84.6 \%$ and specificity of 86.4 The AUC of the ROC curve was $0.856(\mathrm{p}<0.000)$. 

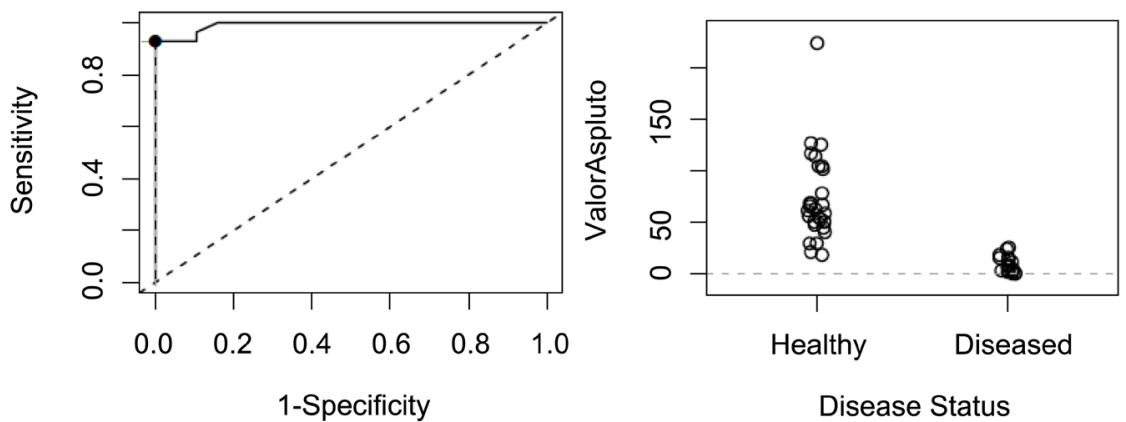

1-Specificity

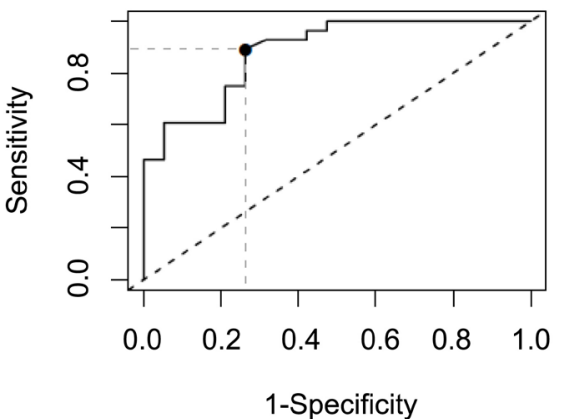

(A)

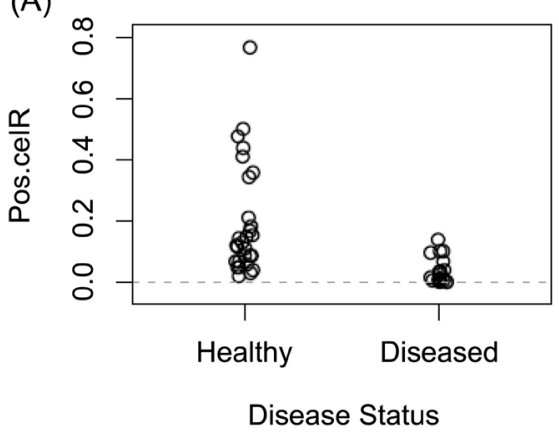

(B)
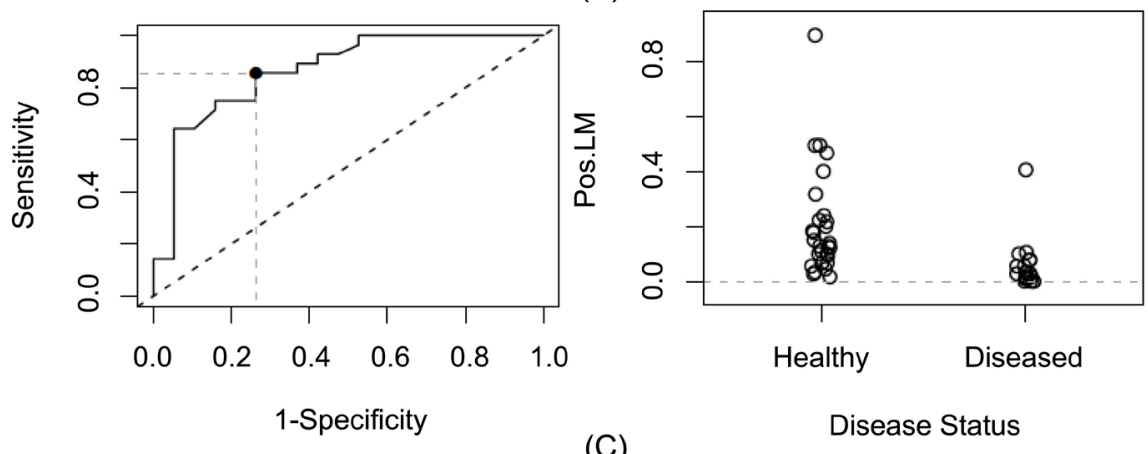

Figure 2. GITR co-inhibitor could segregate nonrejection (NR) patients from those with acute rejectin (AR). The score model was practiced on $28 \mathrm{NR}$ and 19 AR samples to generate a scale Q score ranging from 0 to 100 for Valor Absoluto (VA) and from 0 to 1 for PosCelR and PosLM ratios. The AUC of the ROC curves and the disribution of NR and AR are shown in the figure. (A) For VA the Youden optimal cut-off method set a threshold at 29 with a corresponding sensitivity of $92.9 \%$ and specificity of $100 \%$. The AUC of the ROC curve was 0.992 ( $\mathrm{p}<0.000$ ). (B) For the ratio PosCelR the Youden optimal cut-off method set a threshold at 0.047 with a corresponding sensitivity of $89.3 \%$ and specificity of $73.7 \%$. The AUC of the ROC curve was $0.883(\mathrm{p}<0.000)$. (C) For the ratio PosLM the Youden optimal cut-off method set a threshold at 0.06 with a corresponding sensitivity of $85.7 \%$ and specificity of $73.7 \%$. The AUC of the ROC curve was 0.866 ( $\mathrm{p}<$ $0.000)$.

occurred in nine patients, being that six cases within the first month, one on day 120 and two on day 300 post-transplantation. Results for the absolute number of positive cells in Fnab samples were $36.8 \pm 54.4$ (IQR: 8 - 37), $14.2 \pm 23.6$ (IQR: 3 - 10) and $7.4 \pm 6.4$ (IQR: 4 - 7) for stable CNI, RAPA and anti-IL2 $\alpha$ R antibody, respectively and $30.3 \pm 49.1$ (IQR: 4 - 16) for acute rejection. There were no significant differences by analysing the three therapeutics although a trend was ob- 
served for ILT- 4 down-regulation both by RAPA, P $=0.1$ and by anti-IL $2 \alpha$ R antibody, $\mathrm{P}=0.08$. Also, the ratio of positives cells over either $\mathrm{R}$ cells or LM cells did not show any significant difference.

\section{Discussion}

Our study highlights a significantly strong difference in intra-graft expression of PD-L2 and GITR and a significant difference for ILT-2/3/5 on comparing clinically stable KTx with those developing acute rejection. Meanwhile such a difference was not observed for ILT-4 that nonetheless exhibited a close to significant modulation when RAPA substituted for MMF and when anti-IL2 $\alpha \mathrm{R}$ antibody was added to the immunosuppressive regimen.

$\mathrm{PD}-\mathrm{L} 2$ is one of the two ligands for PD-1 and the triad PD-1/PD-L1/PD-L2 is involved in both central [18] and peripheral tolerance through multiple mechanisms [19] [20] [21]. Of major health importance, it seems to be one of the pathways tumours explore to evade immune surveillance [22] while on the other hand, some chemotherapeutics promote the anti-tumour $\mathrm{T}$ cell response through reducing PD-L2 on both APC and tumour cells [23]. PD-L1 actions have been described in several models of transplantation. While APC transfected with adenovirus coding for PD-L1 is able to enhance kidney transplant survival in fully mismatched rats [24], a decreased PD-L1 expression by renal tubular epithelial cells in human KTx has been associated with the development of a more intense cellular acute rejection although a paradoxical PD-L1 up-regulation has been observed in human KTx undergoing acute vascular rejection [25].

We preferred to focus our study on PD-L2 once the reports regarding it have been contradictory and scarce. Some studies described APC and T cell activation by PD-L2 [26] [27], others saw that PD-L2 deficient mice display diminished IFN $\gamma$ synthesis by naïve CD4 T cells and down-regulated IFN $\gamma$-dependent humoral and cytotoxic $\mathrm{T}$ lymphocyte responses [28]. Still others showed that $\mathrm{CD} 4^{+}$ $\mathrm{T}$ cells activated by PD-L2 ${ }^{-/-}$APC synthesize higher amounts of IL- 2 and IFN $\gamma$ [20] and associate PD-L2 blocking with the exacerbation of experimental autoimmune encephalomyelitis [29]. Others showed that PD-L2 negatively regulates $\mathrm{T}$ cell activation in vitro and in vivo and plays a unique function in oral tolerance in PD-L2 knockout mice [30]. Beyond this controversy, and quite the opposite, PD-L1 is constitutively present and further enhanced on activated lymphocytes, APC and non-hematopoietic cell types which are commonly observed in Fnab samples, namely, vascular endothelial cells and kidney tubular cells [25] [31]. Thus, PD-L2 restriction to dendritic cells and macrophages [31], appeared to us very interesting. It is important to remember that PD-L2 is endowed with a three times higher binding affinity to PD-1 in comparison to PD-L1 [32] and PD-1 engagement by PD-L2 may down-regulate T cell proliferation by affecting Akt and Ras pathways [33], limiting glucose metabolism and ATP synthesis [34], and decreasing cytokine production by $\mathrm{CD} 4^{+} \mathrm{T}$ cells, which may turn to be its main effect at high antigen concentration [35] which most 
likely constitutes the KTx scenario. Also, it should be noted that the translation of PD-L2 observations in mouse models of transplantation into human picture should be tempered by the significant difference of the cytoplasmic domains, with the mouse version being only four amino acids long and the human bearing thirty amino acids. Although this longer form has no known signalling motifs, its conservation in a number of mammals (but not rodents) seems to underpin a functionality [36]. Our findings for PD-L2 show a very different picture when comparing stable cases with acute rejection. Our study included only one observation per patient. In stable KTx, Fnab was done mainly at the end of the first week post-surgery, suggesting that the organ infiltration by PD-L2+ APC is done quite early. However, Fnab procured during the second-third week post-KTx, did not display any significant difference compared to the observations seen in the first week, which could suggest PD-L2 ${ }^{+}$APC cells remain inside the graft or are permanently renovated. Alternatively to $\mathrm{PD}-\mathrm{L} 2$ positivation before infiltrating KTx, one may speculate that in stable cases, infiltrating APC up-regulate PD-L2 expression in situ depending on a particular $\mathrm{T}$ cell receptor binding strength by the alloantigen or on a particular cytokine/chemokine milieu. Of relevance, PD-L2 expression did not revealed any correlation with CNI blood levels although those were significantly lower in acute rejection and PD-L2 was significantly down-regulated. Our results do not confirm those reported by C. Afaneh [37] who employed a different methodology looking at the urinary cell levels of mRNA for PD-L2 and PD-L1 among other molecules and did not find any difference between stable and acute rejection KTx patients, neither did he found any difference when comparing different grades of acute rejection. Limited by human studies imponderables we were not able to gather the pretended number of KTx under different treatment protocols.

Our observations for GITR paralleled the ones for PD-L2. A very significant and strong difference was observed when comparing GITR up-regulated stable KTx and acute rejection cases. Actually, an astonishingly high negative and especially positive predictive value was reached just by quantifying the GITR positives cells. Of notice the significant, albeit not strong, correlation observed between PD-L2 and GITR in a subgroup of twenty-three KTx that could be tested simultaneously. Also some controversial findings have been produced dealing with GITR actions. GITR is over-expressed in regulatory T cells [38] and naïve resting regulatory $\mathrm{T}$ cells along with a weak expression of CTLA-4, Lag3, IL-10, IL-35 and Granzyme-B, which exhibit a complete demethylation of the noncoding DNA sequence 2 of FoxP3 [39] [40]. Of importance, in murine lung cancer models, regulatory $\mathrm{T}$ cells infiltrating the tumour express high levels of GITR and anti-GITR therapy improved survival [41]. However, there is evidence that GITR is not a specific marker for regulatory $\mathrm{T}$ cell since GITR can either stimulate or inhibit suppressor activity [41]. Furthermore, GITR is not confined to T cells. It is expressed on NK cells, polymorphonuclear cells, monocytes-macrophages, B cells, dendritic cells and mast cells. Clearly, the final outcome of GITR trig- 
gering is dependent on the particular experimental system and can result in stimulation or inhibition of the immune response [42] [43] [44] [45] [46]. Actually, while it seems that, at least in several allotransplantation animal models, blockade of GITR interaction with its ligand prolongs allograft survival [47], the outcome of GITR binding on macrophages seems to be an accelerated proliferation and migration of inflammatory macrophages, together with enhancement of phagocytic and killing ability in a mouse model of bacterial peritonitis [48]. Contrary to what is observed in this mouse model, additional data has been gathered with GITR positive $T$ regulatory cells that infiltrate several tumours in humans [49]. Those can be seen as a special kind of transplant, being that in humans, GITR has been associated with the synthesis of IL-13, which promotes the development of alternatively activated macrophages that are associated with anti-inflammatory [50] properties and amelioration of type 2 diabetes.

Certainly, our findings so clearly different for the presence of GITR cells that infiltrate stable cases, "quiescent" KTx may just be a reflection of the intra-graft presence of T regulatory cells which display the highest expression of GITR. On the other hand, the one log lower presence of GITR cells during acute rejection no matter how long the transplantation was done, would not match a concept of regulatory $\mathrm{T}$ cell presence as a counter-regulation to be observed during acute rejection, only. To say that GITR positivity in graft-infiltrating cells is causally related to KTx freedom of rejection is obviously and scientifically unfounded while at the same time denying any role to this, seems to be not compatible with our concepts of biological evolution. It will be difficult to reproduce an animal model of what we are reporting as there is reason to believe that GITR actions depend heavily on the presence of a special mixture of other players.

Our observations concerning ILT-2/3/5 were not so much discriminating as those produced by PD-L2 and GITR, although the statistics for ILT-2/3/5 were probably influenced by the inferior number of cases. Nonetheless, and in accordance with our expectations, it did present a significant up-regulation in Fnab samples from stable KTx but contrary to others [14] [51] its expression was not significantly influenced by RAPA, although a trend to a down-regulation was also observed in our study $(\mathrm{P}=0.28)$. Unexpectedly, ILT-4 did not present a difference when comparing stable cases with acute rejection but of interest, we did observe a close to significant down-regulation of ILT-4 within stable cases either when anti-IL2 $\alpha$ R antibody was used $(\mathrm{P}=0.08)$ or when RAPA substituted for MMF $(\mathrm{P}=0.1)$. We speculate that if we had the opportunity to include a larger number of cases, these differences could reach a significance level, in line with those observed for ILT-4 by others [14] [51]. Said that, because it is important to acknowledge that still other authors observed in human renal transplants an induction of ILT- $3^{\text {high }}$ and ILT- $4^{\text {high }}$ dendritic cells by RAPA [52]. ILTs are receptors structurally and functionally related to killer-cell inhibitory receptors [53] and they can be subdivided into two main types, the second one including ILT-2, ILT-3, ILT-4, and ILT-5, all endowed with a cytoplasmic immune-receptor tyrosine-based inhibitory motif, which when activated become 
phosphorylated and recruit $\mathrm{p} 56^{\mathrm{lck}}$ and src homology 2-containing protein-tyrosine-phosphatase 1 [54]. ILTs are expressed by professional and non-professional APC, including dendritic cells, monocytes-macrophages and endothelial cells [54]. ILT-2 and ILT-4 bind to non-classical MHC HLA-G with a three to four-fold higher affinity than to classical MHC and they compete with CD8 for binding to MHC class I [55], while the expression of ILT-3 and ILT-4 on APC and endothelium is up-regulated by IL-10 promoting the inhibition of proliferation of allogeneic T cells [56] [57]. Also, ILT-4 interacts with native CD1d tetramer through the $\alpha 1$ and $\alpha 2$ domains which constitute the location of the antigen binding groove thus modulating CD1d-mediated antigen presentation [58]. ILT-3 can negatively regulate APC responses to stimulation through $\mathrm{CD} 11 \mathrm{~b}, \mathrm{CD} 16$, and MHC class II, and behaves as an antigen-capturing molecule by targeting its ligand into processing peptide-loading compartments [59]. Evidence has been gathered on immunosuppressive role of ILTs in different human health situations. In lupus patients, ILT-2 and ILT-4 may be either functionally deficient or down-regulated [60] [61], while ILT-4 expression has been found in human tumours [62]. ILT-4 was not found to be expressed in endothelial cells from human heart transplant biopsies done during the first two weeks post-transplantation but later in the follow-up, its presence was significantly higher in biopsies from rejection-free cases as compared to transplants with an acute rejection episode [63]. This observation may explain our results concerning ILT-4 whose expression may appear later than ILT-2/3/5. Actually we have reported that cultures of Fnab samples synthesize significantly higher quantities of IL-10 if the samples were taken from rejection-free cases as compared to acute rejection KTx [64] and one could speculate that for ILT-4 expression one would need a microenvironment rich in IL-10. However, considering the whole of our observations one may speculate that ILTs do not seem to play as much important role as PD-L2 and GITR seem to have in KTx.

We acknowledge that our study has limitations, including the small number of cases admitted to our measurements, to the retrospective character of the study, to our inability to perform serial evaluations for each case. Also, we believe that other treatment strategies may be followed by some differences for the studied molecules, although our immunosuppressive protocol is the current standard of care for KTx. Also, some doubts may be raised if these results will be reproduced in different human organ transplants.

\section{Conclusion}

We report that in human renal transplantation, PD-L2 and GITR seem to share an important role in down-regulating the alloimmune response, and ILT-2/3/5 shows a significant association with rejection-freedom, although not a high one. The strong differences are observed for the first two molecules translated in very high positive and negative predictive values for acute rejection regardless of the time that has elapsed since transplant. Unexpectedly, ILT-4 did not show a significant difference when comparing stable with acute rejection cases. 


\section{Authorship}

Paula Xavier co-designed the research study, performed laboratory work, analysed data and co-wrote the paper. José G. G. Oliveira co-designed the research study, performed aspiration biopsies and laboratory work, collected data and co-wrote the paper.

\section{Funding}

The study was supported by the Research Grant Praxis/PS 214020 from the Portuguese Fundação da Ciência e Tecnologia.

\section{Conflicts of Interest}

The authors declare no conflicts of interest.

\section{References}

[1] Medawar, P.B. (1944) The Behaviour and Fate of Skin Autografts and Skin Homografts in Rabbits. Journal of Anatomy, 78, 176-199.

[2] Hart, A., Smith, J.M., Skeans, M.A., et al. (2019) OPTN/SRTR 2017 Annual Data Report: Kidney. American Journal of Transplantation, 19, 19-123. https://doi.org/10.1111/ajt.15274

[3] Sellarés, J., de Freitas, D.G., Mengel, M., et al. (2012) Understanding the Causes of Kidney Transplant Failure, the Dominant Role of Antibody-Mediated Rejection and Nonadherence. American Journal of Transplantation, 12, 388. https://doi.org/10.1111/j.1600-6143.2011.03840.x

[4] Barrett, A.J., Rezvani, K., Solomon, S., et al. (2003) New Developments in Allotransplant Immunology. Hematology ASH Education Program, 102, 350. https://doi.org/10.1182/asheducation-2003.1.350

[5] Lafferty, K.J. and Woolnough, J. (1977) The Origin and Mechanism of the Allograft Reaction. Immunological Reviews, 35, 231-262. https://doi.org/10.1111/j.1600-065X.1977.tb00241.x

[6] Shipkova, M. and Wieland, E. (2012) Surface Markers of Lymphocyte Activation and Markers of Cell Proliferation. Clinica Chimica Acta, 413, 1338-1349. https://doi.org/10.1016/j.cca.2011.11.006

[7] Bakdash, G., Sittig, S., van Dijk, T., Figuredor, C.G. and de Vries, J.M. (2013) The Nature of Activatory and Tolerogenic Dendritic Cell-Derived Signal II. Frontiers in Immunology, 4, 53. https://doi.org/10.3389/fimmu.2013.00053

[8] Marin, E., Cuturi, M.C. and Moreau, A. (2018) Tolerogenic Dendritic Cells in Solid Organ Transplantation, Where Do We Stand? Frontiers in Immunology, 9, 274. https://doi.org/10.3389/fimmu.2018.00274

[9] Braza, F., Durand, M., Degauque, N. and Brouard, S. (2015) Regulatory T Cells in Kidney Transplantation: New Directions? American Journal of Transplantation, 15, 2288-2300. https://doi.org/10.1111/ajt.13395

[10] Puccetti, P. and Grohmann, U. (2007) IDO and Regulatory T Cells, a Role for Reverse Signalling and Non-Canonical NF- $\kappa$ B Activation. Nature Reviews Immunology, 7, 817-823. https://doi.org/10.1038/nri2163

[11] Truong, W., Hancock, W.W., Anderson, C.C., Merani, S. and Shapiro, M.J. (2006) Coinhibitory T-Cell Signalling in Islet Allograft Rejection and Tolerance. Cell 
Transplantation, 15, 105-119. https://doi.org/10.3727/000000006783982160

[12] Bajwa, R., Cheema, A., Khan, T., et al. (2019) Adverse Effects of Immune Checkpoint Inhibitors (Programmed Death-1 Inhibitors and Cytotoxic T-Lymphocyte-Associated Protein-4 Inhibitors): Results of a Retrospective Study. Journal of Clinical Medicine Research, 11, 225-236. https://doi.org/10.14740/jocmr3750

[13] del Rio, M.-L., Buhler, L., Gibbond, C., Tian, J. and Rodriguez-Barbosa, J.-I. (2008) PD-1/PD-L1, PD-1/PD-L2 and Other Co-Inhibitory Signalling Pathways in Transplantation. Transplant International, 21, 1015-1028. https://doi.org/10.1111/j.1432-2277.2008.00726.x

[14] Fedoric, B. and Krishnan, R. (2008) Rapamycin Downregulates the Inhibitory Receptors ILT2, ILT3, ILT4 on Human Dendritic Cells and Yet Induces T Cell Hyporesponsiveness Independent of FoxP3 Induction. Immunology Letters, 120, 49-56. https://doi.org/10.1016/j.imlet.2008.06.009

[15] Haÿry, P. (1989) Fine-Needle Aspiration Biopsy in Renal Transplantation. Kidney International, 36, 130. https://doi.org/10.1038/ki.1989.172

[16] Xavier, P.D.P., Lema, G.L., Magalhães, M.C., et al. (2014) Flow Cytometry Assessment of Graft-Infiltrating Lymphocytes Can Accurately Identify Acute Rejection in Kidney Transplants. Clinical Transplantation, 28, 177-183. https://doi.org/10.1111/ctr.12293

[17] Oliveira, J.G.G., Ramos, J.P., Xavier, P., Magalhães, M.C., Mendes, A.A. and Guerra, L.E.R. (1997) Analysis of Fine-Needle Aspiration Biopsies by Flow Cytometry in Kidney Transplant Patients. Transplantation, 64, 97-102. https://doi.org/10.1097/00007890-199707150-00018

[18] Blank, C., Brown, L., Marks, R., Nishimura, H., Honjo, T. and Gajewski, T.F. (2003) Absence of Programmed Death Receptor 1 Alters Thymic Development and Enhances Generation of CD4/CD8 Double-Negative TCR-Transgenic T Cells. The Journal of Immunology, 171, 4574-4581. https://doi.org/10.4049/jimmunol.171.9.4574

[19] Probst, H.C., McCoy, K., Okazaki, T., Honjo, T. and van den Broek, M. (2005) Resting Dendritic Cells Induce Peripheral CD8+T Cell Tolerance through PD-1 and CTLA-4. Nature Immunology, 6, 280-286. https://doi.org/10.1038/ni1165

[20] Keir, M.E., Liang, S.C., Guleria, I., et al. (2006) Tissue Expression of PD-L1 Mediates Peripheral T Cell Tolerance. Journal of Experimental Medicine, 203, 883-895. https://doi.org/10.1084/jem.20051776

[21] Fife, B.T., Pauken, K.E., Eagar, T.N., et al. (2009) Interactions between PD-1 and PD-L1 Promote Tolerance by Blocking the TCR-Induced Stop Signal. Nature Immunology, 10, 1185-1192. https://doi.org/10.1038/ni.1790

[22] Curiel, T.J., Wei, S., Dong, H., et al. (2003) Blockade of B7-H1 Improves Myeloid Dendritic Cell-Mediated Anti-Tumor Immunity. Nature Medicine, 9, 562-567. https://doi.org/10.1038/nm863

[23] Lesterhuis, W.J., Punt, C.J., Hato, S.V., et al. (2011) Platinum-Based Drugs Disrupt STAT6-Mediated Suppression of Immune Responses against Cancer in Humans and Mice. Journal of Clinical Investigation, 121, 3100-3108. https://doi.org/10.1172/JCI43656

[24] Peng, W., Ran, B., Ma, Y., Huang, X., Chang, Q. and Wang, X. (2011) Dendritic Cells Transfected with PD-L1 Recombinant Adenovirus Induces T Cell Suppression and Long-Term Acceptance of Allograft Transplantation. Cellular Immunology, 271, 73-77. https://doi.org/10.1016/j.cellimm.2011.06.007

[25] Starke, A., Lindenmeyer, M.T., Segerer, S., et al. (2010) Renal Tubular PD-L1 
(CD274) Suppresses Alloreactive Human T-Cell Responses. Kidney International, 78, 38-47. https://doi.org/10.1038/ki.2010.97

[26] Nguyen, L.T., Radhakrihnan, S., Ciric, B., et al. (2002) Cross-Linking the B7 Family Molecule B7-DC Directly Activates Immune Functions of Dendritic Cells. Journal of Experimental Medicine, 196, 1393-1398. https://doi.org/10.1084/jem.20021466

[27] Radhakrihnan, S., Nguyen, L.T., Ciric, B., et al. (2003) Naturally Occurring Human IgM Antibody That Binds B7-DC and Potentiates T Cell Stimulation by Dendritic Cells. The Journal of Immunology, 170, 1830-1838. https://doi.org/10.4049/jimmunol.170.4.1830

[28] Shin, T., Yoshimura, K., Shin, T., et al. (2005) In Vivo Costimulatory Role of B7-DC in Tuning T Helper Cell 1 and Cytotoxic T Lymphocyte Responses. Journal of EXperimental Medicine, 201, 1531-1541. https://doi.org/10.1084/jem.20050072

[29] Salama, A.D., Chitnis, T., Imitola, J., et al. (2003) Critical Role of Programmed Death-1 (PD-1) Pathway in Regulation of Experimental Autoimmune Encephalomyelitis. Journal of Experimental Medicine, 198, 71-78. https://doi.org/10.1084/jem.20022119

[30] Zhang, Y., Chung, Y., Bishop, C., et al. (2006) Regulation of T Cell Activation and Tolerance by PDL2. Proceedings of the National Academy of Sciences of the United States of America, 103, 11695-11700. https://doi.org/10.1073/pnas.0601347103

[31] Greenwald, R.J., Freeman, G.J. and Sharpe, A.H. (2005) The B7 Family Revisited. Annual Review of Immunology, 23, 515-548.

https://doi.org/10.1146/annurev.immunol.23.021704.115611

[32] Butte, M.J., Keir, M.E., Phamduy, T.B., Sharpe, A.H. and Freeman, G.J. (2007) Programmed Death-1 Ligand 1 Interacts Specifically with the B7-1 Costimulatory Molecule to Inhibit T Cell Responses. Immunity, 27, 111-122. https://doi.org/10.1016/j.immuni.2007.05.016

[33] Patsoukis, N., Brown, J., Petkova, V., Liu, F., Li, L. and Boussiotis, V.A. (2012) Selective Effects of PD-1 on Akt and Ras Pathways Regulate Molecular Components of the Cell Cycle and Inhibit T Cell Proliferation. Science Signaling, 5, ra46. https://doi.org/10.1126/scisignal.2002796

[34] Chemnitz, J.M., Parry, R.V., Nichols, K.E., June, C.H. and Riley, J.I. (2004) SHP-1 and SHP-2 Associate with Immunoreceptor Tyrosine-Based Switch Motif of Programmed Death 1 upon Primary Human T Cell Stimulation, But Only Receptor Ligation Prevents T Cell Activation. The Journal of Immunology, 173, 945-954. https://doi.org/10.4049/jimmunol.173.2.945

[35] Latchman, Y., Wood, R.C., Chernova, T., et al. (2001) PD-L2 Is a Second Ligand for PD-1 and Inhibits T Cell Activation. Nature Immunology, 2, 261-268.

https://doi.org/10.1038/85330

[36] Riella, L.V., Paterson, A.M., Sharpe, A.H. and Chandraker, A. (2012) Role of the PD-1 Pathway in the Immune Response. American Journal of Transplantation, 12, 2575-2587. https://doi.org/10.1111/j.1600-6143.2012.04224.x

[37] Afaneh, C., Muthukumar, T., Lubetzky, M., et al. (2010) Urinary Cell Levels of mRNA for OX40, OX40L, OD-1, PD-L1 or PD-L2 and Acute Rejection of Human Renal Allografts. Transplantation, 90, 1381-1387. https://doi.org/10.1097/TP.0b013e3181ffbadd

[38] McHugh, R.S., Whitters, M.J., Piccirillo, C.A., Young, D.A., Shevach, E.M., Collins, M. and Byrne, M.C. (2002) CD4(+)CD25(+) Immunoregulatory T Cells, Gene Expression Analysis Reveals a Functional Role for the Glucocorticoid-Induced TNF Receptor. Immunity, 16, 311-323. https://doi.org/10.1016/S1074-7613(02)00280-7 
[39] Miyara, M., Yoshioka, Y., Kitoh, A., et al. (2009) Functional Delineation and Differentiation Dynamics of Human CD4+T Cells Expressing the FoxP3 Transcription Factor. Immunity, 30, 899-911. https://doi.org/10.1016/j.immuni.2009.03.019

[40] Valmori, D., Merlo, A., Souleimanian, N.E., Hesdorffer, C.S. and Ayyoub, M. (2005) A Peripheral Circulating Compartment of Natural Naïve CD4 Tregs. Journal of Clinical Investigation, 115, 1953-1962. https://doi.org/10.1172/JCI23963

[41] Schoenhals, J.E., Cushman, T.R., Barsoumian, H.B., et al. (2018) Anti-GlucocorticoidInduced Tumor Necrosis Factor-Related Protein (GITR) Therapy Overcomes Radiation-Induced Treg Immunosuppression and Drives Abscopal Effects. Frontiers in Immunology, 9, 2170. https://doi.org/10.3389/fimmu.2018.02170

[42] Nocentini, G., Ronchetti, S., Cuzzocrea, S. and Riccardi, C. (2007) GITR/GITRL, More than an Effector T Cell Costimulatory System. European Journal of Immunology, 37, 1165-1169. https://doi.org/10.1002/eji.200636933

[43] Li, Y., Yang, S., Li, Z., Meng, H., Jin, W., Yang, H. and Yin, W. (2019) Soluble Glucorcoticoid-Induced Tumor Necrosis Factor Receptor Regulates Helios Expression in Myasthenia Gravis. Journal of Translational Medicine, 17, 168-177. https://doi.org/10.1186/s12967-019-1916-1

[44] Zhang, M., Wan, J., Xu, Y., et al. (2017) Simultaneously Increased Expression of Glucocorticoid-Induced Tumor Necrosis Factor Receptor and Its Ligand Contributes to Increased Interleukin-5/13-Producing Group 2 Innate Lymphocytes in Murine Asthma. Molecular Medicine Reports, 15, 4291-4299. https://doi.org/10.3892/mmr.2017.6500

[45] Liao, G., Nayak, S., Regueiro, J.R., et al. (2010) GITR Engagement Preferentially Rnhances Proliferation of Functionally Competent $\mathrm{CD} 4{ }^{+} \mathrm{CD} 25^{+} \mathrm{FoxP} 3^{+}$Regulatory T Cells. International Immunology, 22, 259-270. https://doi.org/10.1093/intimm/dxq001

[46] Clouthier, D.L. and Watts, T.H. (2014) Cell-Specific and Context-Dependent Effects of GITR in Cancer, Autoimmunity, and Infection. Cytokine \& Growth Factor Reviews, 25, 91-106. https://doi.org/10.1016/j.cytogfr.2013.12.003

[47] Kim, J.I., Sonawane, S.B., Lee, M.L., et al. (2010) Blockade of GITR-GITRL Interaction Maintains Treg Function to Prolong Allograft Survival. European Journal of Immunology, 40, 1369-1374. https://doi.org/10.1002/eji.200940046

[48] Fu, Z., Wang, S., Li, J., Zhang, Y., Li, H., Li, G., Wan, X. and Zhang, Y. (2020) Biological Role of GITR/GITRL in Attributes and Immune Responses of Macrophage. Journal of Leukocyte Biology, 107, 309-321. https://doi.org/10.1002/JLB.3A0919-387RR

[49] Knee, D.A., Hewes, B. and Brogdon, J.L. (2016) Rationale for Anti-GITR Cancer Immunotherapy. European Journal of Cancer, 67, 1-10.

https://doi.org/10.1016/j.ejca.2016.06.028

[50] Galle-Treger, Snakaranarayanan, I., Hurrell, B.P., et al. (2019) Costimulation of Type-2 Inate Lymphoid Cells by GITR Promotes Effector Function and Ameliorates Type 2 Diabetes. Nature Communications, 10, 713. https://doi.org/10.1038/s41467-019-08449-x

[51] Karimi, M., Ahmadpoor, P., Nafar, M., Pourrezagholi, F., Jamali, S., Eteghadi, A. Yekaninejad, M.S. and Amirzargar, A.A. (2020) Frequency of Dendritic Cell Subsets and ILT3, ILT4 Gene Expression in Two Different Immunosuppressive Protocols in Kidney Transplant Recipients. A Cohort Report. Molecular Biology Reports, 47, 123-128. https://doi.org/10.1007/s11033-019-05113-x

[52] Stallone, G., Pontrelli, P., Infante, B., Gigante, M., Netti, G., Ranieri, E., Grandalia- 
no, G. and Gesualdo, L. (2014) Rapamycin Induces ILT3 ${ }^{\text {high }}$ and ILT4 ${ }^{\text {high }}$ Dendritic Cells Promoting a New Immunoregulatory Pathway. Kidney International, 85, 888-897. https://doi.org/10.1038/ki.2013.337

[53] Yokoyama, W.M. (1997) What Goes Up Must Come Down, the Emerging Spectrum of Inhibitory Receptors. Journal of Experimental Medicine, 186, 1803-1808. https://doi.org/10.1084/jem.186.11.1803

[54] Ravetch, J.V. and Lanier, L.L. (2000) Immune Inhibitory Receptors. Science, 290, 84-89. https://doi.org/10.1126/science.290.5489.84

[55] Shiroishi, M., Tsumoto, K., Amano, K., et al. (2003) Human Inhibitory Receptors Ig-Like Transcript 2 (ILT2) and ILT4 Compete with CD8 for MHC Class I Binding and Bind Preferentially to HLA-G. Proceedings of the National Academy of Sciences of the United States of America, 100, 8856-8861. https://doi.org/10.1073/pnas.1431057100

[56] Beinhauer, B.G., McBride, J.M., Graf, P., et al. (2004) Interleukin 10 Regulates Cell Surface and Soluble LIR-2 (CD85d) Expression on Dendritic Cells Resulting in T Cell Hyporesponsiveness in Vitro. European Journal of Immunology, 34, 74-80. https://doi.org/10.1002/eji.200324550

[57] Manavalan, J.S., Rossi, P.C., Vlad, G., et al. (2003) High Expression of ILT3 and ILT4 Is a General Feature of Tolerogenic Dendritic Cells. Transplant Immunology, 11, 245-258. https://doi.org/10.1016/S0966-3274(03)00058-3

[58] Li, D., Wang, L., Yu, L., Freundt, E.C., Jin, B., Screaton, G.R. and Xu, X.-N. (2009) Immunoglobulin-Like Transcript 4 (ILT4) Inhibits Lipid Antigen Presentation through Direct CD1d Interaction. The Journal of Immunology, 15, 1033-1040. https://doi.org/10.4049/jimmunol.182.2.1033

[59] Cella, M., Döhring, C., Samaridis, J., Dessing, M., Brockhaus, M., Lanzavecchia, A. and Colonna, M. (1997) A Novel Inhibitory Receptor (ILT3) Expressed on Monocytes, Macrphages, and Dendritic Cells Involved in Antigen Processing. Journal of Experimental Medicine, 10, 1743-1751. https://doi.org/10.1084/jem.185.10.1743

[60] Monsiváis-Urenda, A., Niño-Moreno, P., Abud-Mendoza, C., et al. (2007) Analysis of Expression and Function of the Inhibitory Receptor ILT2 (CD85j/LILRB1/LIR-1) in Peripheral Blood Mononuclear Cells from Patients with Systemic Lupus Erythematosus (SLE). Journal of Autoimmunity, 29, 97-105.

https://doi.org/10.1016/j.jaut.2007.05.003

[61] Guerra-de-Blas, P., Villaseñor-Talavera, Y.S., Cruz-González, D.J., Baranda, L., Doníz-Padilla, L., Abud-Mendoza, C., González-Amaro, R. and Monsiváis-Urenda, A.E. (2016) Analysis of the Expression and Function of Immunoglobulin-Like Transcript 4 (ILT4, LILRB2) in Dendritic Cells from Patients with Systemic Lúpus Erythematosus. Journal of Immunology Research, 7, 1-13. https://doi.org/10.1155/2016/4163094

[62] Sun, Y., Liu, J., Gao, P., Wang, Y. and Liu, C. (2008) Expression of Ig-Like Transcript 4 Inhibitory Receptor in Human Non-Small Cell Lung Cancer. Chest, 134, 783-788. https://doi.org/10.1378/chest.07-1100

[63] Manavalan, J.S., Kim-Sculze, S., Scotto, L., et al. (2004) Alloantigen Specific $\mathrm{CD}^{+} \mathrm{CD} 28^{-} \mathrm{FOXP}^{+}{ }^{+} \mathrm{T}$ Suppressor Cells Induce ILT3 ${ }^{+} \mathrm{ILT}^{+}{ }^{+}$Tolerogenic Endothelial Cells, Inhibiting Alloreactivity. International Immunology, 16, 1055-1068. https://doi.org/10.1093/intimm/dxh107

[64] Oliveira, G., Xavier, P., Murphy, B., Neto, S., Mendes, A., Sayegh, M.H. and Guerra, L.E. (1998) Cytokine Analysis of Human Renal Allograft Aspiration Biopsy Cultures Supernatants Predicts Acute Rejection. Nephrology Dialysis Transplantation, 13, 417-422. https://doi.org/10.1093/oxfordjournals.ndt.a027839 


\section{Abbreviations}

anti-IL2 $\alpha \mathrm{R}$ : anti-IL2 $\alpha$ receptor

APC: Antigen-presenting cell

CNI: Calcineurin inhibitors

Fnab: Fine-needle aspiration biopsy

GITR: Glucocorticoid-induced tumor necrosis factor receptor

ILT: Immunoglobulin-like transcript

KTx: Kidney transplant

PD-L2: Programmed death-ligand 2

PRA: Panel of reactive antibodies 